\title{
Article \\ Photodynamic Therapy and Multi-Modality Imaging of Up-Conversion Nanomaterial Doped with AuNPs
}

\author{
Wei Zhang ${ }^{1}{ }^{(}$, Yanli Lu ${ }^{1}$, Yang Zang ${ }^{1}$, Jinhui Han ${ }^{2}$, Qingyun Xiong ${ }^{1}$ and Jinping Xiong ${ }^{1,3, *(\mathbb{D}}$ \\ 1 Beijing Key Laboratory of Electrochemical Process and Technology of Materials, School of Materials Science \\ and Engineering, Beijing University of Chemical Technology, Beijing 100029, China; \\ 2019200387@mail.buct.edu.cn (W.Z.); 2019310036@mail.buct.edu.cn (Y.L.); \\ 2019310030@mail.buct.edu.cn (Y.Z.); 2020200494@mail.buct.edu.cn (Q.X.) \\ 2 State Key Laboratory of Organic-Inorganic Composites, School of Chemical Engineering, School of Materials \\ Science and Engineering, Beijing University of Chemical Technology, Beijing 100029, China; \\ 2021400008@buct.edu.cn \\ 3 College of Ecology and Resources Engineering, Wuyi University, Wuyishan 354300, China \\ * Correspondence: xiongjp@mail.buct.edu.cn
}

Citation: Zhang, W.; Lu, Y.; Zang, Y.; Han, J.; Xiong, Q.; Xiong, J. Photodynamic Therapy and Multi-Modality Imaging of Up-Conversion Nanomaterial Doped with AuNPs. Int. J. Mol. Sci. 2022, 23, 1227. https://doi.org/10.3390/ ijms23031227

Academic Editor: Raphaël Schneider

Received: 4 January 2022

Accepted: 19 January 2022

Published: 22 January 2022

Publisher's Note: MDPI stays neutral with regard to jurisdictional claims in published maps and institutional affiliations.

Copyright: (C) 2022 by the authors. Licensee MDPI, Basel, Switzerland. This article is an open access article distributed under the terms and conditions of the Creative Commons Attribution (CC BY) license (https:// creativecommons.org/licenses/by/ $4.0 /)$.

\begin{abstract}
Two key concerns exist in contemporary cancer chemotherapy in clinic: limited therapeutic efficiency and substantial side effects in patients. In recent years, researchers have been investigating a revolutionary cancer treatment technique, and photodynamic therapy (PDT) has been proposed by many scholars. A drug for photodynamic cancer treatment was synthesized using the hydrothermal method, which has a high efficiency to release reactive oxygen species (ROS). It may also be utilized as a clear multi-modality bioimaging platform for photoacoustic imaging (PAI) due to its photothermal effect, computed tomography (CT), and magnetic resonance imaging (MRI). When compared to singlemodality imaging, multi-modality imaging delivers far more thorough and precise details for cancer diagnosis. Furthermore, Au-doped up-conversion nanoparticles (UCNPs) have an exceptionally high luminous intensity. The Au-doped UCNPs, in particular, are non-toxic to tissues without laser at an $808 \mathrm{~nm}$ wavelength, endowing the as-prepared medications with outstanding therapeutic efficacy but exceptionally low side effects. These findings may encourage fresh effective imaging-guided approaches to meet the goal of photodynamic cancer therapy to be created.
\end{abstract}

Keywords: up-conversion; nanomaterials; photodynamic; multi-modality imaging

\section{Introduction}

Interest in developing theranostic nanoplatforms with simultaneous diagnostic and therapeutic capacity has gradually increased in the nanomedicine field because it provides significant prospects in the treatment of major illnesses including cancer [1]. Imaging probes, as one of the most important components of the theranostic nanoplate-form, should be able to perform many levels of imaging at the same time, from the cell to the whole body, to offer comprehensive tumor characteristics for clinical diagnostics. However, singlemodality imaging did not match the high diagnostic criteria since each imaging technique (optical imaging, CT, and MRI) has intrinsic flaws due to restricted resolution, sensitivity, or imaging depths.

To mitigate this problem, several imaging probes were combined into a single multimodality imaging system, which contained some considerable restrictions such as sophisticated synthetic processes and heterogeneous nanostructures. As a result of their enhanced optical and magnetic properties, and also improved X-ray attenuation, lanthanide-doped upconverting nanoparticles (UCNPs) might be perfect for building multifunctional bio probes by doping with various rare earth ions without modifying other functions.

Many researchers have recently advocated that this system be employed in biological imaging since it provides considerable benefits in the treatment against major illnesses 
such as cancer. However, the typical challenge is that it has insufficient light intensity and is poisonous to biological cells; therefore, its structure and surface must be modified [2]. Many scholars have proposed doping $\mathrm{Mo}^{3+}, \mathrm{Cu}^{2+}[3,4]$, and other metal ions in the $\mathrm{NaYF}_{4}: \mathrm{Yb}^{3+} / \mathrm{Er}^{3+}$ unit cell to increase the luminous intensity $[5,6]$, but the effect is not significant. Others have offered sliver doping [7], which has a large impact as well; however, sliver is poisonous to cells, may cause cell death without targeting, and cannot be employed in biology. Many scholars have proposed constructing core-shell structures such as $\mathrm{NaYF}_{4}: \mathrm{Yb}^{3+} / \mathrm{Er}^{3+} @ \mathrm{NaGdF}_{4}: \mathrm{Yb}^{3+}$ and $\mathrm{NaYF}_{4}: \mathrm{Yb}^{3+} / \mathrm{Er}^{3+} @ \mathrm{NaNdF}_{4}: \mathrm{Yb}^{3+} / \mathrm{Tm}^{3+} @ \mathrm{NaGdF}_{4}: \mathrm{Yb}^{3+}[8-10]$. Alternatively, use the reverse microemulsion method to construct a layer of silica or porous silica, such as $\mathrm{NaYF}_{4}: \mathrm{Yb}^{3+} / \mathrm{Er}^{3+} @ \mathrm{SiO}_{2}$, or $\mathrm{NaYF}_{4}: \mathrm{Yb}^{3+} / \mathrm{Er}^{3+} @ \mathrm{NaGdF}_{4}: \mathrm{Yb}^{3+} @ \mathrm{~m}-$ $\mathrm{SiO}_{2}$ [11-14]. Au nanoparticles (AuNPs) are currently the mainstream biomaterials in tumor diagnosis and treatment applications $[15,16]$. They are widely used in CT imaging and photoacoustic imaging due to their excellent imaging capabilities and photothermal effects [17]. However, in our research, their photothermal stability seems not to be very good [18]. Unfortunately, when these materials meet the biological requirements, they will inevitably reduce their luminous intensity, so that imaging cannot be performed to obtain a clear image $[19,20]$. Considering the high desire to develop UCNPs nanomaterials with highly effective imaging capability as well as high biocompatibility to prevent apoptosis or biological organ failure, UCNPs doped with Au nanoparticles (AuNPs) are an ideal candidate because they are easy to fabricate, have enhanced luminescence, and are easy to surface modify $[7,21]$. More notably, following illumination, the UCNPs are harmless to normal tissues but cytotoxic to malignancies. To the best of our knowledge, however, there appears to be a failure in the literature to yet create theranostic nanoplatforms integrating multi-modality bioimaging with light trigger chemotherapy.

\section{Results and Discussion}

The TEM images of gold nanoparticles (Figure S1) prepared using the hydrothermal method show that they are spherical and have an average diameter of $5 \mathrm{~nm}$. TEM images show the morphology of Au-UCNPs (Figure S2). They are rod structures with a length of 50-100 $\mathrm{nm}$ and have narrow ends. The reason for this phenomenon is that during the nucleation and growth of the nanoparticles by the coprecipitation-hydrothermal method, the temperature controls its width and shape, and the time determines its length. When the temperature starts to drop, the two ends of the nanorod begin to shrink with the decrease in temperature, and finally show the phenomenon of narrowing at both ends. The successful doping of gold nanoparticles into UCNPs was proved by energy spectrum (Figure S3).

The content of ROS released by different concentrations of Au-UCNPs-DSPE-PEG $2 \mathrm{~K}$ under near-infrared light with wavelength of $808 \mathrm{~nm}$ was measured by Singlet Oxygen Sensor Green (SOSG). As can be seen from Figure 1, Au-UCNPs-DSPE-PEG $2 \mathrm{~K}$ hardly releases ROS without irradiation. The amount of ROS increased with the increase in Au-UCNPs-DSPE-PEG $2 \mathrm{~K}$ concentration and time.

Compared with the contrast ability of Au-UCNPs-DSPE-PEG $2 \mathrm{~K}$, its particularity lies in its photothermal conversion efficiency (Figure 2). It is excited by near-infrared light at a $980 \mathrm{~nm}$ wavelength, it is observed by a thermal imager that it not only emits green fluorescence [21], but also emit heat. Combined with its biocompatibility, Au-UCNPs$\mathrm{DSPE}_{-\mathrm{PEG}} \mathrm{K}_{\mathrm{K}}$ can be considered as a photothermal therapy reagent (Figures S4 and S5). The reason for this phenomenon is that gold will generate heat when irradiated by a $540 \mathrm{~nm}$ laser, while rare earth up-conversion nanomaterials excited by a $980 \mathrm{~nm}$ near-infrared light will emit $540 \mathrm{~nm}$ fluorescence. Secondly, the doping of silver nanoparticles will enhance the energy of a $540 \mathrm{~nm}$ wavelength. Finally, the energy of a $540 \mathrm{~nm}$ wavelength excites the silver nanoparticles, making the silver nanoparticles release heat. Incidentally, the carrier properties of a $540 \mathrm{~nm}$ laser, a $980 \mathrm{~nm}$ near-infrared light, and $540 \mathrm{~nm}$ fluorescence are the same, and the photothermal results also show that. Simultaneously, AuNPs enhance the luminescence intensity of UCNPs under the near-infrared light with the wavelength of $980 \mathrm{~nm}$, so that UCNPs emit stronger light energy with the wavelength of $540 \mathrm{~nm}$. This 
light energy further excites AuNPs, resulting in the heat emission of UCNPs doped with AuNPs [22].

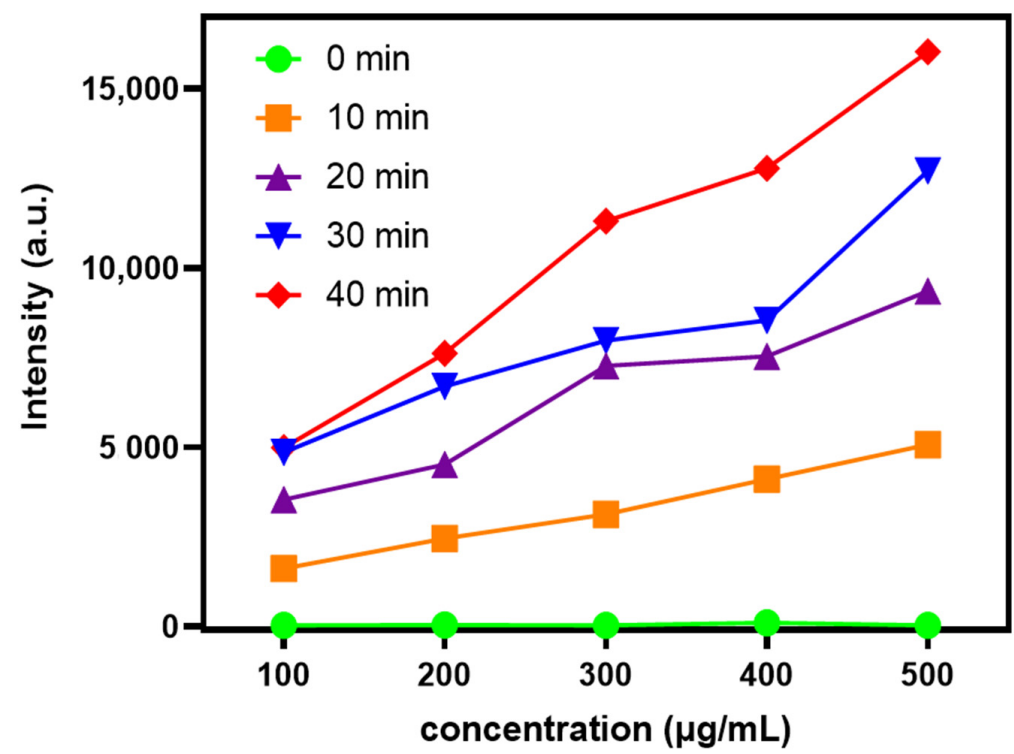

Figure 1. ROS generation by different concentration of Au-UCNPs-DSPE-PEG $2 \mathrm{~K}$ was evaluated under near infrared irradiation at $808 \mathrm{~nm}$ for different time.

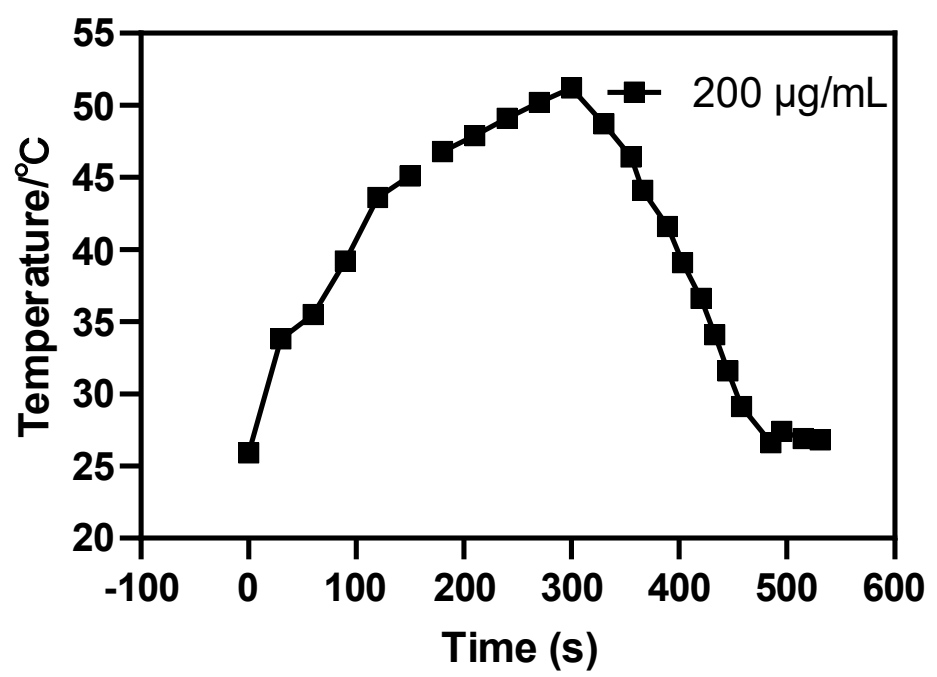

Figure 2. The $980 \mathrm{~nm}$ wavelength of near-infrared light excites the temperature rising-falling curve of $200 \mu \mathrm{g} / \mathrm{mL}$ of Au-UCNPs-DSPE-PEG $2 \mathrm{~K}$.

In order to observe the ROS produced by Au-UCNPs-DSPE-PEG $2 \mathrm{~K}$ and its effect on cells more intuitively, it was monitored by flow cytometry (Figure 3). ROS are molecules that contain hydroxyl radicals or peroxides with unpaired electrons. In healthy aerobic cells, ROS is naturally generated at a controlled rate as oxidation products of oxidative phosphorylation, oxidoreductase, or metal catalysis. However, it may be induced under some stress conditions, especially exposure to environmental oxidants and some drugs leading to release ROS. Excessive ROS may destroy cellular components including DNA, proteins, and lipids, and eventually lead to cell death. Cell permeability $2^{\prime}, 7^{\prime}$-dichlorodihydrofluorescein diacetate (DCFH-DA) is a widely used ROS indicator. The reduced non-fluorescein h2dcfda can be oxidized by intracellular ROS and converted into fluorescent $2^{\prime}, 7^{\prime}$-dichlorofluorescein (DCF). Therefore, Figure 3 labels intracellular ROS with DCFH-DA and detects the strength of DCF by flow cytometry. 

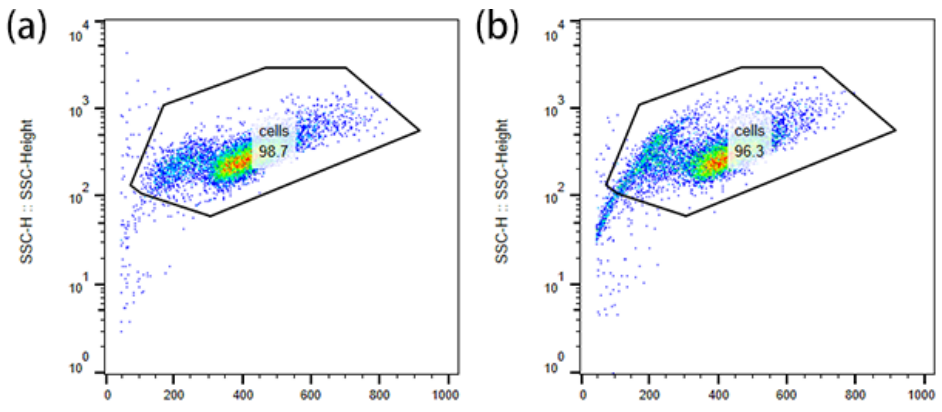

(f)
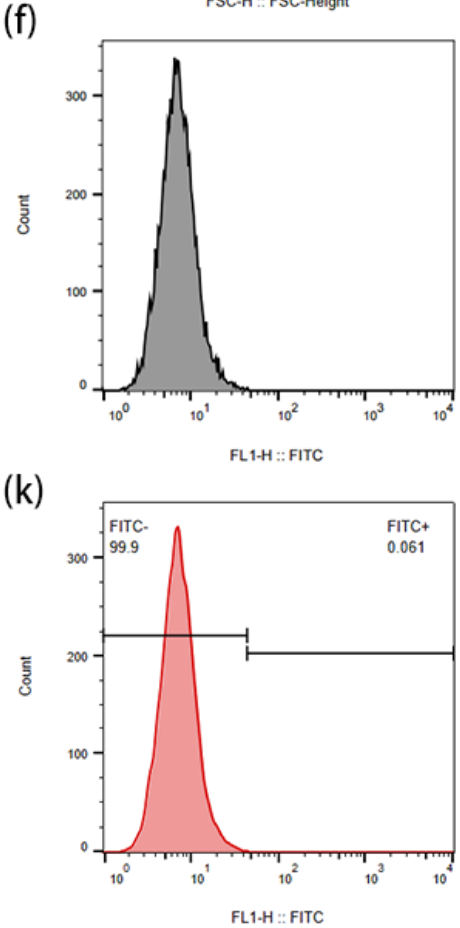

(g)
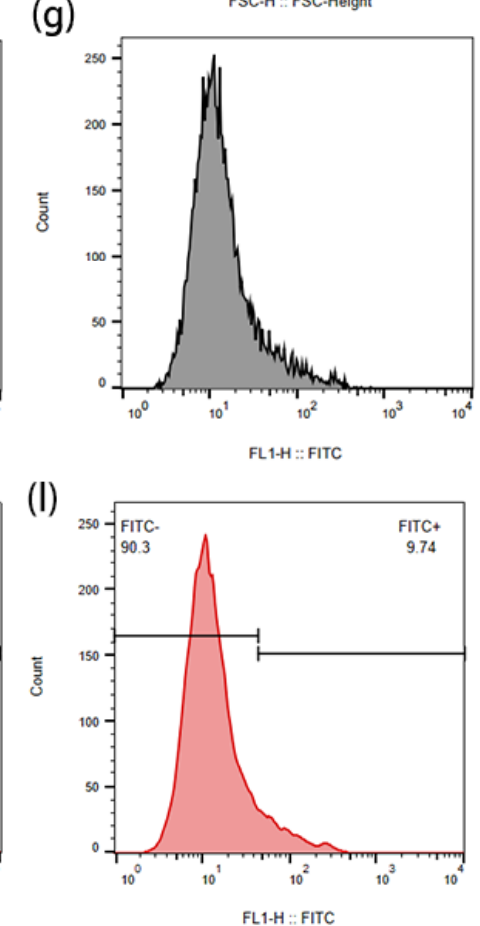

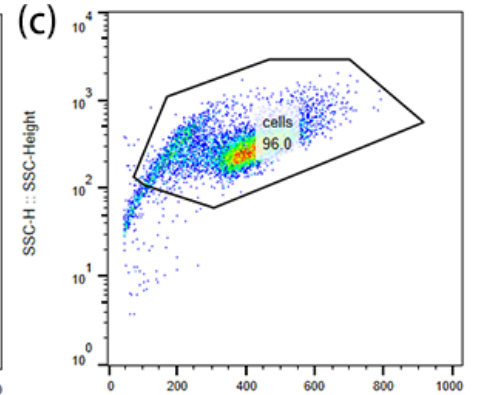

(h)

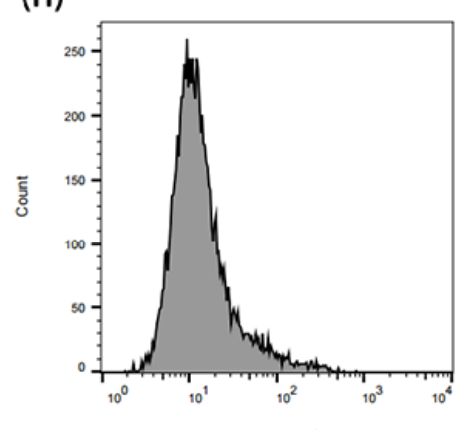

(m)

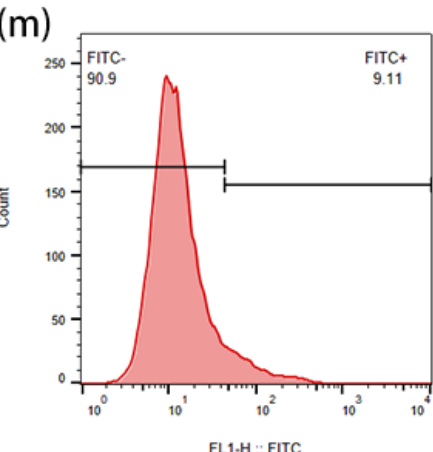

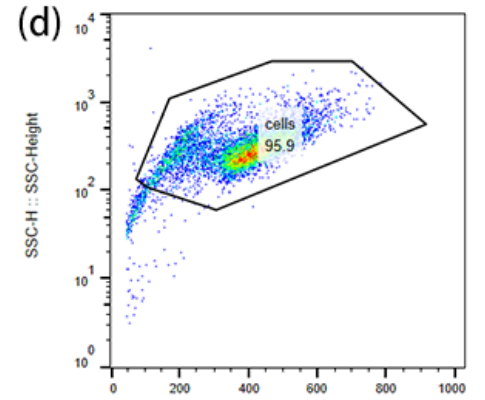

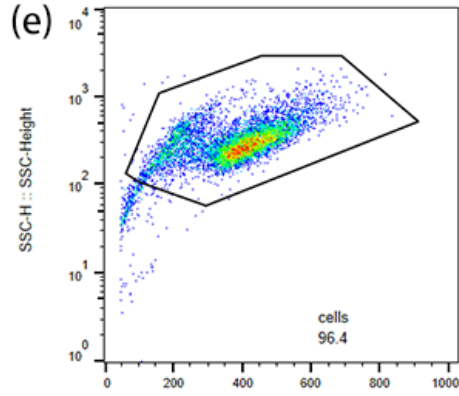

(i)

FSC.H : FSC.Height

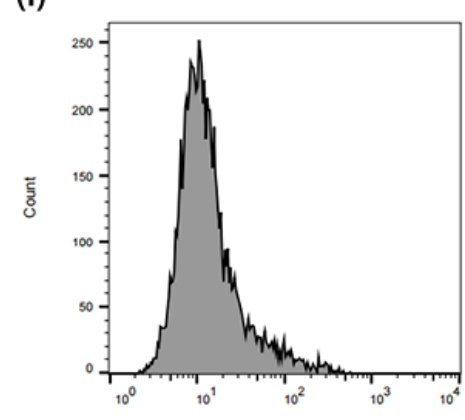

FUH FITC

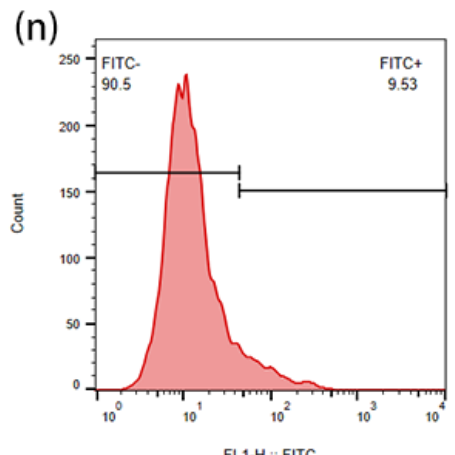

(j)

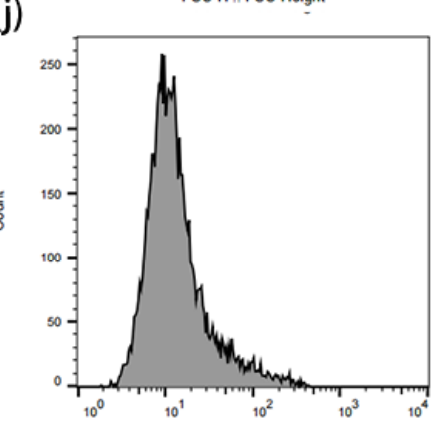

FL 1 H: : FITC

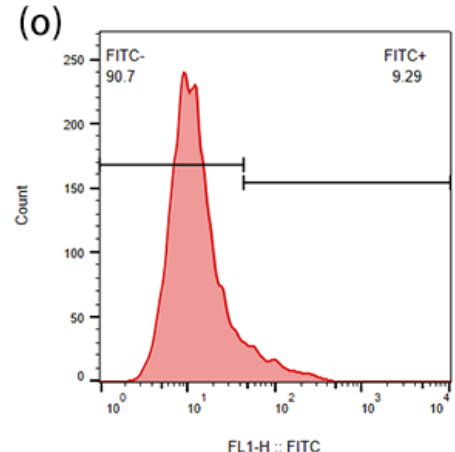

Figure 3. The effect of ROS produced by Au-UCNPs-DSPE-PEG ${ }_{2 K}$ under laser on cells and the change in fluorescence intensity after DCFH-DA staining were measured by flow cytometry: (a): blank; (b-e): laser for $0 \mathrm{~min}, 10 \mathrm{~min}, 20 \mathrm{~min}$, and $30 \mathrm{~min}$, respectively, after adding Au-UCNPs-DSPE-PEG $2 \mathrm{~K}$; (f-j): corresponding to the fluorescence intensity of $(\mathbf{a}-\mathbf{e}, \mathbf{k}-\mathbf{o})$ : the negative and positive areas of $(\mathbf{a}-\mathbf{e})$. 
It can be seen from Figure 3a-e that the cells initially gathered at one place. After adding Au-UCNPs-DSPE-PEG ${ }_{2 K}$ and laser, there were two groups in the cell community, which indicates that under the laser, Au-UCNPs-DSPE-PEG $2 \mathrm{~K}$ produced a large amount of ROS (Figure 1). A large amount of ROS destroyed the cells and turned the cells into fragments, resulting in two groups of cell communities, that is, one group was cell fragments. Figure $3 \mathrm{f}-\mathrm{j}$ also confirmed this, which can be seen, with the addition of Au-UCNPs-DSPE$\mathrm{PEG}_{2 \mathrm{~K}}$ and laser, the fluorescein peak shifted to the right, that is (Figure 4), the fluorescence was enhanced. In other words, the amount of dye DCFH-DA converted into DCF by ROS increased.

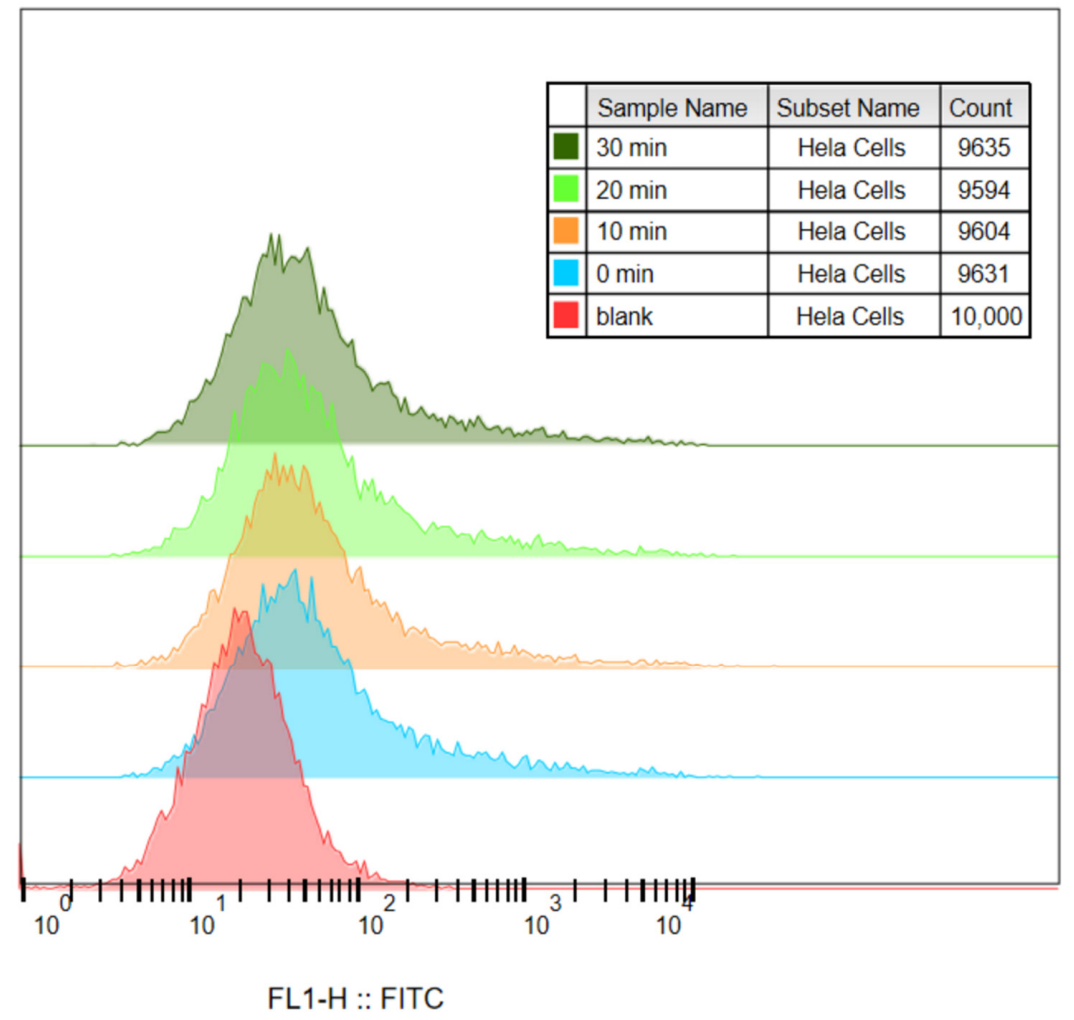

Figure 4. Histogram of Figure 3a-e.

The cytotoxicity of Au-UCNPs-DSPE-PEG ${ }_{2 K}$ is tested by enzyme labeling instrument. HeLa cells are cultivated for $4 \mathrm{~h}$ after dispersing modified rare-earth nanomaterials in normal saline to prepare various quantities, and their activity is assessed (Figure 5). The cell survival rate is greater than $89 \%$ at the concentration of Au-UCNPs-DSPE-PEG $2 \mathrm{~K}$ is less than $400 \mu \mathrm{g} / \mathrm{mL}$. Particularly, at $200 \mu \mathrm{g} / \mathrm{mL}$, the cell survival rate is greater than $99 \%$. According to Figure 2, a $200 \mu \mathrm{g} / \mathrm{mL}$ concentration of rare-earth nanoparticles not only has appropriate safety but also has a high luminous intensity. Even when the rare-earth ion concentration is as high as 500 or $600 \mu \mathrm{g} / \mathrm{mL}$, cell survival remains greater than $80 \%$. Moreover, under the irradiation of near-infrared light with the wavelength of $808 \mathrm{~nm}, \mathrm{ROS}$ was produced, which caused the apoptosis of cells (Figure S6).

$\mathrm{Au}$ and $\mathrm{Au}-\mathrm{DSPE}-\mathrm{PEG}_{2 \mathrm{~K}}$ nanoparticles are injected intravenously into Balb/c mice (Figure 6). As can be seen from Figure 6a,b, there is no difference in MRI images before and after Au nanoparticles injection, demonstrating that AuNPs have no MRI imaging capabilities due to their lack of X-ray attenuation. After injection of Au-UCNPs nanoparticles, obvious MRI signals appear at the tumor location (in the red circle in Figure 6d), which is due to the X-ray attenuation characteristics of UCNPs (Figure S7).

Figure 7 shows that, although AuNPs have imaging ability (Figure 7b), it needs a very high concentration, while Au-UCNPs needs a low concentration (Figure S8), which is why very obvious CT signal is detected (Figure 7f). AuNPs and Au-UCNPs are at the same concentration, and Au cannot observe CT signal (Figure 7d). 


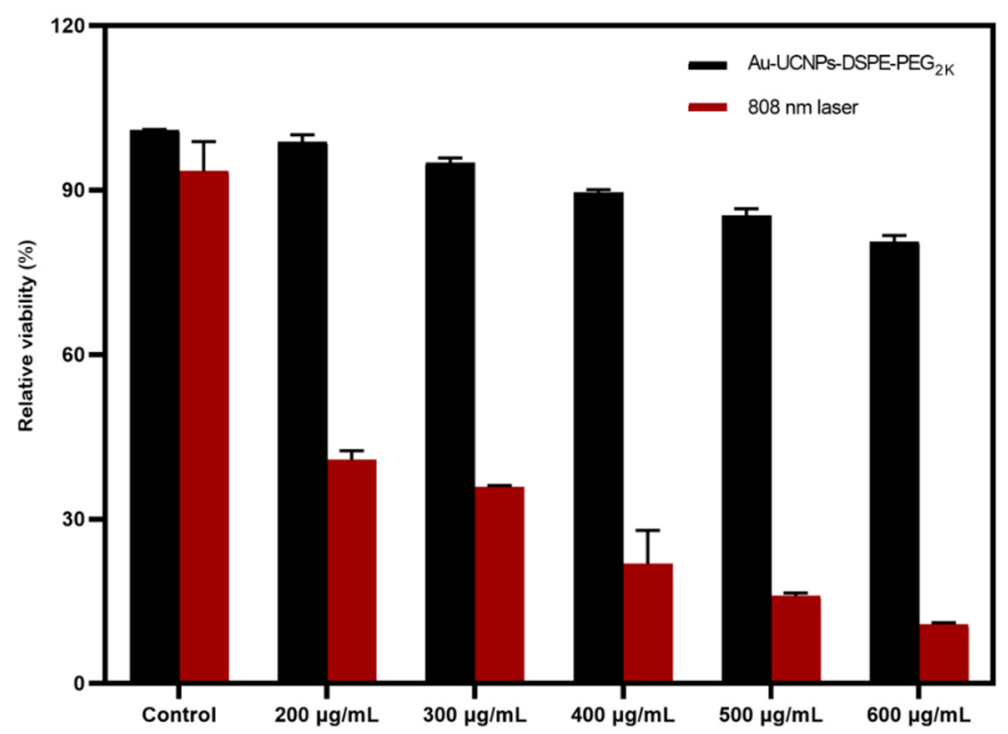

Figure 5. Cytotoxicity of different concentrations of Au-UCNPs-DSPE-PEG $2 \mathrm{~K}$ and in $808 \mathrm{~nm}$ laser.

(a)

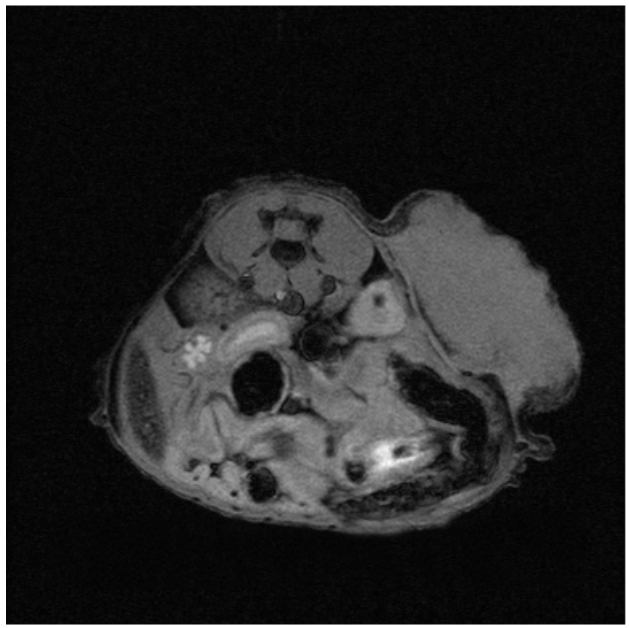

(c)

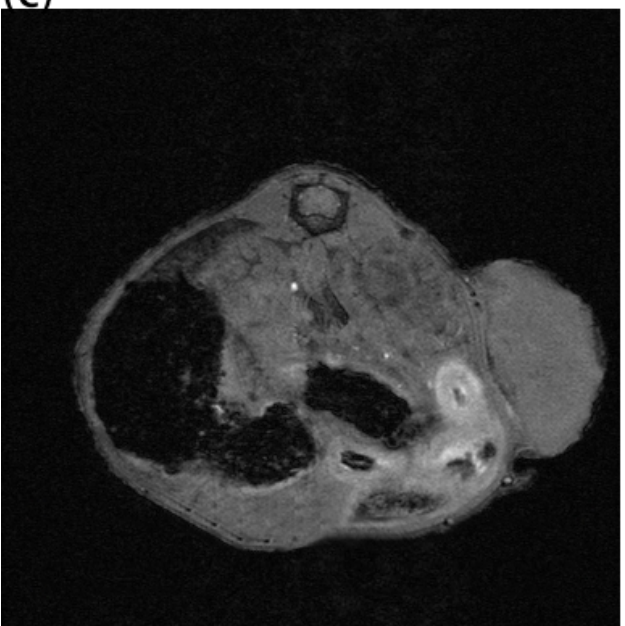

(b)

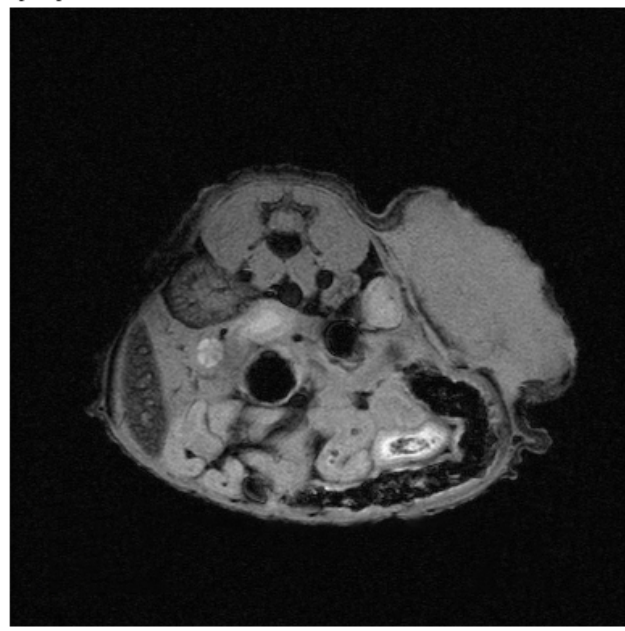

(d)

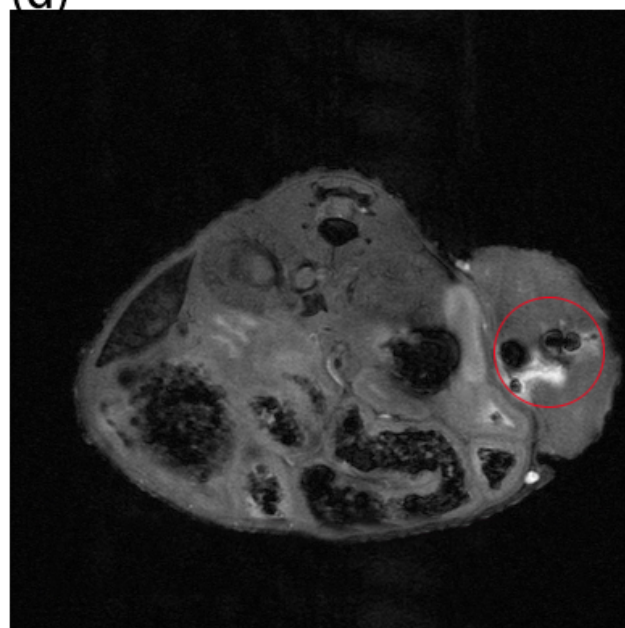

Figure 6. MR images before and after intratumor injection of $\mathrm{Au}$ and Au-UCNPs-DSPE-PEG $2 \mathrm{~K}$ in Balb/c mice, $(\mathbf{a}, \mathbf{b})$ are before and after injection of $\mathrm{Au},(\mathbf{c}, \mathbf{d})$ are before and after injection of $\mathrm{Au}-\mathrm{UCNPs}-\mathrm{DSPE}-\mathrm{PEG}_{2 \mathrm{~K}}$, and MR value shown in red circle in $(\mathbf{d})$. 
(a)

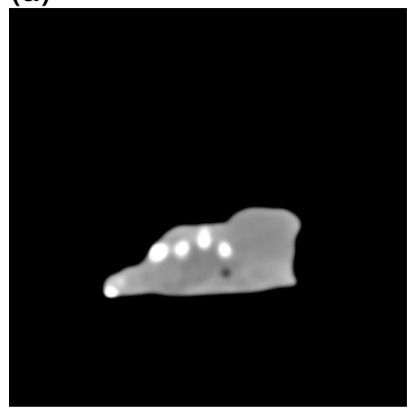

(b)

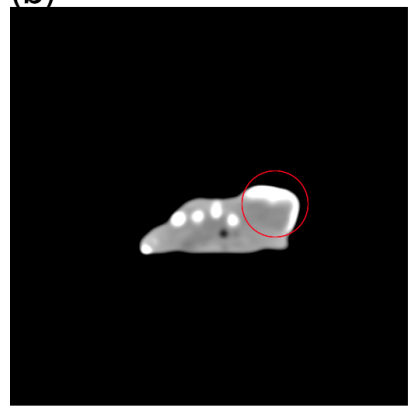

(c)

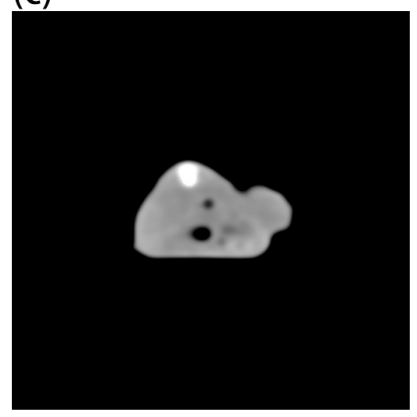

(d)

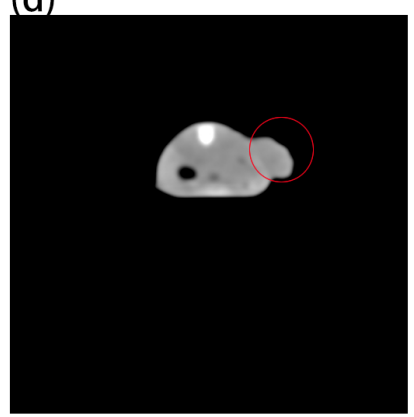

(e)

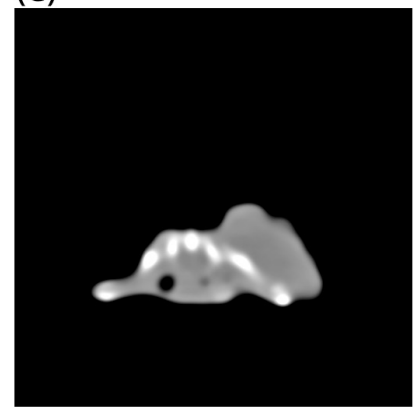

(f)

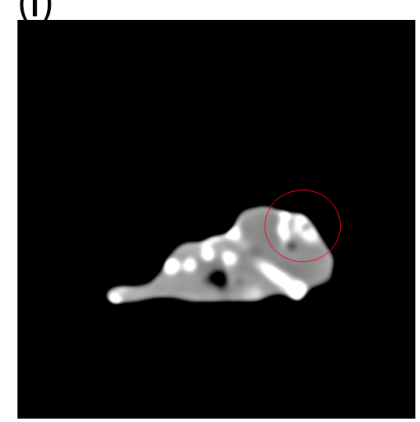

Figure 7. Micro-CT images before and after intratumor injection of $\mathrm{Au}$ and Au-UCNPs-DSPE-PEG $2 \mathrm{~K}$ in Balb/c mice, $(\mathbf{a}, \mathbf{b})$ are before and after injection of high concentration $(50 \mathrm{mg} / \mathrm{mL})$ of $\mathrm{Au},(\mathbf{c}, \mathbf{d})$ are before and after injection of low concentration $(200 \mu \mathrm{g} / \mathrm{mL})$ of $\mathrm{Au},(\mathbf{e}, \mathbf{f})$ are before and after injection of $200 \mu \mathrm{g} / \mathrm{mL}$ of Au-UCNPs-DSPE-PEG ${ }_{2 K}$, and CT value shown in red circle in $(\mathbf{b}, \mathbf{d}, \mathbf{f})$.

Au-UCNPs-DSPE-PEG ${ }_{2 K}$ has excellent photoacoustic properties because of its excellent photothermal effect, which are characterized by photoacoustic imaging (Figure 8), and strong photoacoustic signals can be observed. Figure 9 shows that when injection the concentration of Au-UCNPs-DSPE- PEG $_{2 \mathrm{~K}}$ is $200 \mu \mathrm{g} / \mathrm{mL}$, PA value is very obvious.

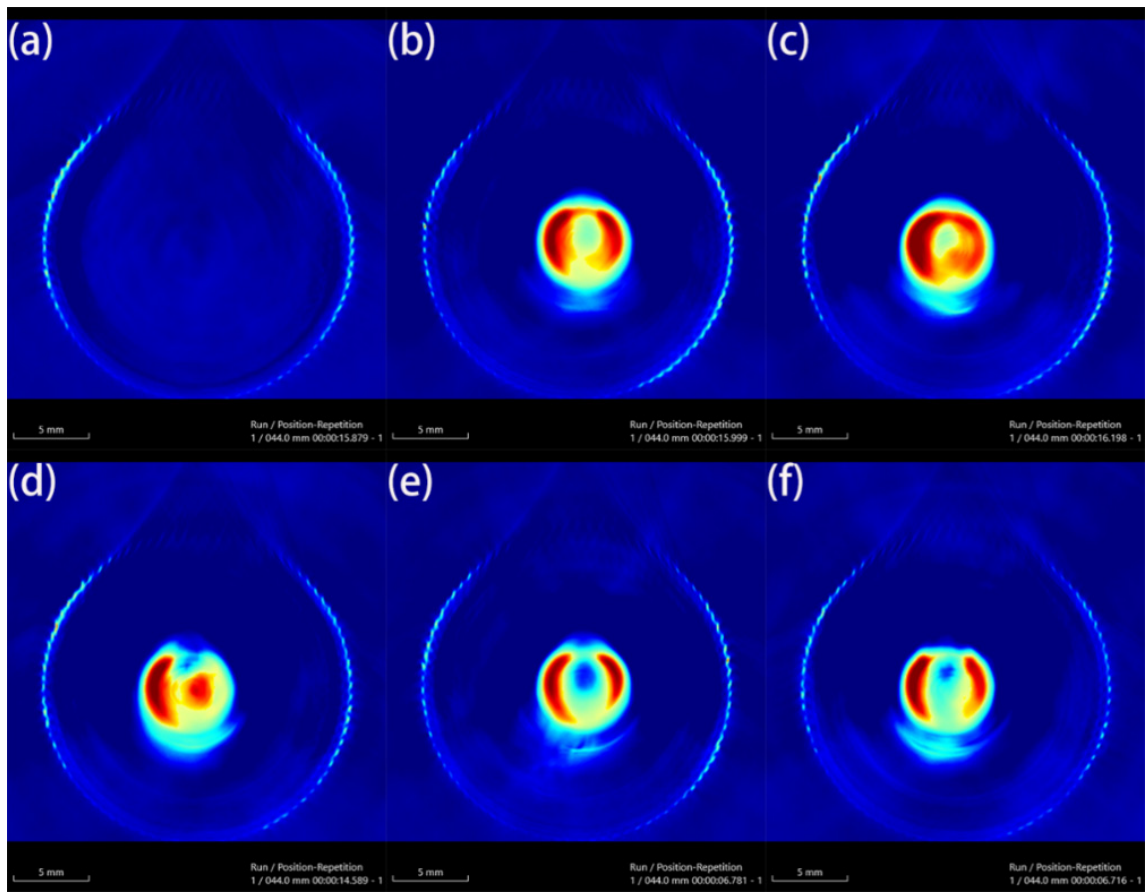

Figure 8. Photoacoustic imaging (PAI) of different concentrations of Au-UCNPs-DSPE-PEG $2 \mathrm{~K},(\mathbf{a}): 0 \mu \mathrm{g} / \mathrm{mL}$, (b): $100 \mu \mathrm{g} / \mathrm{mL},(\mathbf{c}): 200 \mu \mathrm{g} / \mathrm{mL},(\mathbf{d}): 300 \mu \mathrm{g} / \mathrm{mL},(\mathbf{e}): 400 \mu \mathrm{g} / \mathrm{mL},(\mathbf{f}): 500 \mu \mathrm{g} / \mathrm{mL}$. 

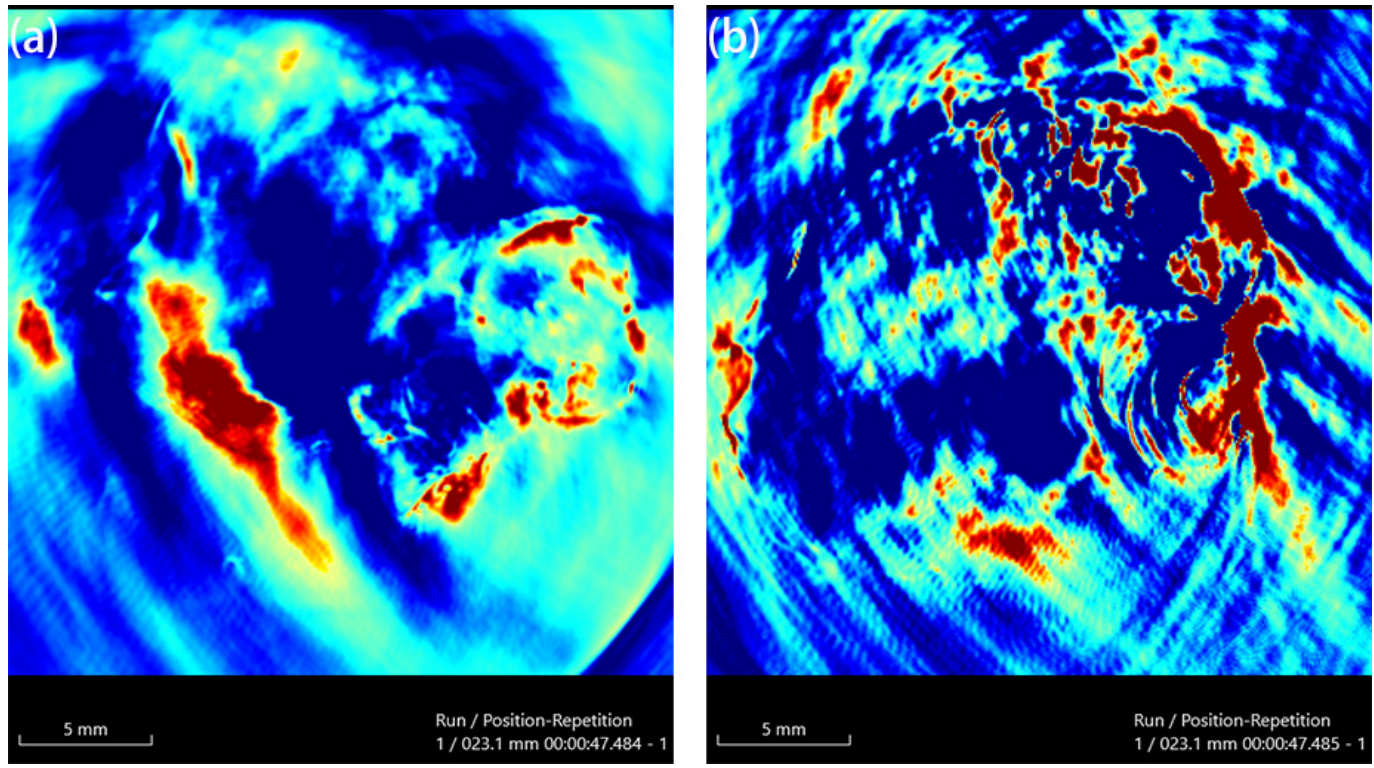

Figure 9. PAI of before (a) and after (b) injection $200 \mu \mathrm{g} / \mathrm{mL}$ of Au-UCNPs-DSPE-PEG $2 \mathrm{~K}$ in Balb/c mice.

\section{Materials and Methods}

\subsection{Materials}

The Au nanoparticles and Au-UCNPs-DSPE-PEG $2 \mathrm{~K}$ were synthesized in Beijing Key Laboratory of Electrochemical Process and Technology of Materials, Beijing University of Chemical Technology, Beijing, China [23]. Hela cells and BALB/c female white mice with SPF grade come from Beijing Laboratory of Biomedical Materials, Beijing University of Chemical Technology, Beijing, China. The cell counting kit 8 (CCK-8) assay kit was acquired from BOVOGEN Shanghai, China. All chemicals were utilized in as-received condition, without further refinement.

\subsection{Characterization of Materials}

A spectrum analyzer (ANDO AQ6317, Yokohama, Japan) was used to obtain the up-conversion luminescence spectra. The specimen was positioned in a $1.0 \mathrm{~cm}$ path length support and excited by utilizing a $980 \mathrm{~nm} \mathrm{CW}$ semiconductor diode laser (Pmax $800 \mathrm{~mW}, 1000 \mathrm{~mA}$ ). The up-conversion luminescence spectrum was acquired through the spectrophotometer having a multimode fiber with a core diameter of $0.6 \mathrm{~mm}$. The top of the fiber was $\sim 2 \mathrm{~mm}$ away from the specimen. Thermal imager (FOCUS 280DS) was used to characterize the photoacoustic properties of photographic materials. HORIBA laser and power density meter are used to characterize photothermal properties.

\subsection{CCK-8 Assay for Cytotoxicity}

HeLa cells were cultured in the logarithmic growth phase, and the culture medium was sucked out from the flask. The cells were then washed with PBS, and digested with the help of $0.25 \%$ trypsin. Then the trypsin was removed, and the cells were blown with DMEM media containing 10\% fetal bovine serum before being shifted to the sample tank and blown well. Following that, $100 \mu \mathrm{L}$ cells were introduced onto a 96-well plate $\left(1 \times 10^{4}\right.$ cells /well $)$ and cultured for $24 \mathrm{~h}$ at $37{ }^{\circ} \mathrm{C}$ in a constant temperature incubator $\left(5 \% \mathrm{CO}_{2}\right)$. The cells were cultured in an incubator at $37^{\circ} \mathrm{C}$ with $5 \% \mathrm{CO}_{2}$ for $1.5 \mathrm{~h}$ at concentrations of 200, 300, 400, 500, and $600 \mu \mathrm{g} / \mathrm{mL}$ of Au-UCNPs-DSPE-PEG ${ }_{2 \mathrm{~K}}$, respectively. The culture media was blotted out, PBS was washed twice, and the culture medium in the 96-well plates was replaced with $100 \mu \mathrm{L}$ of fresh DMEM containing $10 \%$ fetal bovine serum, followed by $10 \mu \mathrm{L}$ of CCK-8 solution in each well. After $2 \mathrm{~h}$ of incubation, the absorbance of each well at $450 \mathrm{~nm}$ was measured with a microplate reader. 


\subsection{SOSG Assay for ROS}

Firstly, $100 \mu \mathrm{g}$ SOSG was dissolved in $6600 \mu \mathrm{L}$ of oxygen-free methanol solution and prepared as a mother liquor with a concentration of $15 \mu \mathrm{g} / \mathrm{mL}$, and then stored away from light for later use. Then, a sample solution $(200 \mu \mathrm{g} / \mathrm{mL})$ was prepared, $100 \mu \mathrm{L}$ was taken and mixed in a 96-well plate with $50 \mu \mathrm{L}$ the SOSG mother liquor, and then irradiated with near-infrared light with a wavelength of $980 \mathrm{~nm}$ (irradiance $0.5 \mathrm{~W} / \mathrm{cm}^{2}$ ) for $0,10,20,30$, and $40 \mathrm{~min}$, each concentration was set to three repeated values and finally passed the spectrometer, which measured the fluorescence intensity of SOSG at $525 \mathrm{~nm}$, and also detected other concentrations $(300,400,500$, and $600 \mu \mathrm{g} / \mathrm{mL})$ in the same way.

\subsection{Establishment of Animal Tumor Model}

A BALB/c female white mouse with SPF grade weighing $18 \mathrm{~g}$ was depilated, and log phase Hela cells were subcutaneously injected into the mice's upper right hind leg to create a mouse Hela subcutaneous tumor development model.

\subsection{MRI, PAI, and CT Imaging of Mice}

To acquire preimages, the mice were anesthetized with isoflurane during the procedure, then placed in an animal MRI scanner (NM42-040H-I) with a magnetic field strength of $1 \mathrm{~T}$, and a tomographic scan was executed of the tumor location on mice whose tumor developed to $100 \mathrm{~mm}^{3}$. Then, $200 \mu \mathrm{g} / \mathrm{mL}$ of Au-UCNPs-DSPE-PEG $2 \mathrm{~K}$ solution was injected, and images were collected again. Similarly, the mouse was placed on a SPECT/CT (tube current: $615 \mu \mathrm{A}$, tube voltage: $55 \mathrm{kV}$ ) animal bed, a preimage acquisition of full-angle CT imaging in precise mode was performed, and then the tomographic image of the tumor site was acquired again after the injection of $200 \mu \mathrm{g} / \mathrm{mL}$ of Au-UCNPs-DSPE-PEG ${ }_{2 \mathrm{~K}}$ solution. Using the same method, the images of mouse tumors before and after injection $(200 \mu \mathrm{g} / \mathrm{mL}$ of Au-UCNPs-DSPE-PEG ${ }_{2 K}$ solution) were obtained in the small animal photoacoustic imaging system (Nexus 128).

\section{Conclusions}

An Au-UCNPs-DSPE-PEG ${ }_{2 K}$ multi-modality bioimaging device was ultimately developed and may be utilized for photodynamic treatment. The combined PA imaging with $\mathrm{CT}$ and MRI experiments show that Au-UCNPs-DSPE-PEG $2 \mathrm{~K}$ may be used as contrast mediators for tri-modal imaging for both in vitro and in vivo testing, giving complete details for tumor diagnosis. Particularly, Au-UCNPs-DSPE-PEG ${ }_{2 K}$ has a good release of ROS to destroy tumor cells to achieve the purpose of tumor treatment. These nanomaterials have exhibited low cytotoxicity, indicating their high biocompatibility for organisms. All these promising findings make Au-UCNPs-DSPE-PEG $2 \mathrm{~K}$ nanocomposites an auspicious candidate for cancer theranostics, and it has encouraged us to develop the integration of diagnosis and treatment of tumors.

Supplementary Materials: The following supporting information can be downloaded at: https: //www.mdpi.com/article/10.3390/ijms23031227/s1.

Author Contributions: Conceptualization, W.Z. and Y.Z.; methodology, J.H.; software, Y.L.; validation, W.Z., Y.Z. and Y.L.; formal analysis, J.H.; resources, Q.X.; data curation, Q.X. and Y.L.; writing-original draft preparation, W.Z.; writing—review and editing, J.X.; supervision, J.X. All authors have read and agreed to the published version of the manuscript.

Funding: This research received no external funding.

Institutional Review Board Statement: Not applicable.

Informed Consent Statement: Not applicable.

Data Availability Statement: No new data were created or analyzed in this study. Data sharing is not applicable to this article. 
Acknowledgments: The authors also would like to thank the Shiyanjia Lab (www.shiyanjia.com, 3 December 2021) for the animal experiments.

Conflicts of Interest: The authors declare no conflict of interest.

\section{References}

1. Alattar, A.M.; Mohammed, R.A.; Alwazzan, M.J.; Twej, W.A. Dispersion of pure silica xerogel vs NaYF4- xerogel nanomaterials in silica aerogel and their effect on the optical and structural properties. Opt. Mater. 2021, 118, 111274. [CrossRef]

2. Ansari, A.A.; Parchur, A.K.; Thorat, N.D.; Chen, G. New advances in pre-clinical diagnostic imaging perspectives of functionalized upconversion nanoparticle-based nanomedicine. Coord. Chem. Rev. 2021, 440, 213971. [CrossRef]

3. Chowdhury, N.; Riesen, N.; Riesen, H. Yb3+ and Er3+ Codoped BaLiF3 Nanocrystals for X-ray Dosimetry and Imaging by Upconversion Luminescence. ACS Appl. Nano Mater. 2021, 4, 6659-6667. [CrossRef]

4. Cordonnier, A.; Boyer, D.; Besse, S.; Valleix, R.; Mahiou, R.; Quintana, M.; Briat, A.; Benbakkar, M.; Penault-Llorca, F.; MaisonialBesset, A.; et al. Synthesis and in vitro preliminary evaluation of prostate-specific membrane antigen targeted upconversion nanoparticles as a first step towards radio/fluorescence-guided surgery of prostate cancer. J. Mater. Chem. B 2021, 9, 7423-7434. [CrossRef]

5. $\quad$ Dong, L.; Zhang, C.; Yan, L.; Zhang, B.; Chen, H.; Mi, X.; Fu, Z.; Zhang, Z.; Zheng, H. Quantifying plasmon resonance and interband transition contributions in photocatalysis of gold nanoparticle. Chin. Phys. B 2021, 9, 077301. [CrossRef]

6. $\quad$ Feng, Z.; Lin, L.; Wang, Z.; Zheng, Z. Highly efficient and wide range low temperature sensing of upconversion luminescence of NaYF4: Er3+ nanoparticles: Effects of concentration of active or sensitive ions, excitation power and particle size on temperature sensing sensitivity. Opt. Commun. 2021, 491, 126942. [CrossRef]

7. Zhang, W.; Lu, Y.; Zang, Y.; Han, J.; Xiong, Q.; Xiong, J. SiO 2 Coated Up-Conversion Nanomaterial Doped with Ag Nanoparticles for Micro-CT Imaging. Nanomaterials 2021, 11, 3395. [CrossRef]

8. Jiang, J.; Ren, H.; Huang, F.; Wang, L.; Zhang, J. Refine the crystallinity of upconversion nanoparticles for NIR-enhanced photocatalysis. CrystEngComm 2021, 23, 6117-6127. [CrossRef]

9. Jones, C.M.S.; Biner, D.; Misopoulos, S.; Krämer, K.W.; Marques-Hueso, J. Optimized photoluminescence quantum yield in upconversion composites considering the scattering, inner-filter effects, thickness, self-absorption, and temperature. Sci. Rep. 2021, 11, 13910. [CrossRef]

10. Zong, H.; Mu, X.; Sun, M. Physical principle and advances in plasmon-enhanced upconversion luminescence. Appl. Mater. Today 2019, 15, 43-57. [CrossRef]

11. Wang, Y.; Xu, W.; Lei, L.; Chen, L.; Ye, R.; Xu, S. Photoluminescent NaGdF4@NaYF4:Ce/Tb inert-core/active-shell nanoparticles for selective and ultra-sensitive Cu2+ ions sensing. J. Lumin. 2021, 235, 118024. [CrossRef]

12. Lu, F.; Zhao, T.; Sun, X.; Wang, Z.; Fan, Q.; Huang, W. Rare-earth Doped Nanoparticles with Narrow NIR-II Emission for Optical Imaging with Reduced Autofluorescence. Chem. Res. Chin. Univ. 2021, 37, 943-950. [CrossRef]

13. Mahata, M.; De, R.; Lee, K. Near-Infrared-Triggered Upconverting Nanoparticles for Biomedicine Applications. Biomedicines 2021, 9, 756. [CrossRef]

14. Murali, G.; Vattikuti, S.P.; Kshetri, Y.K.; Lee, H.; Modigunta, J.K.R.; Reddy, C.S.; Park, S.; Lee, S.; Poornaprakash, B.; Lee, H.; et al. Near-infrared-activated Z-scheme NaYF4:Yb/Tm@Ag3PO4/Ag@g-C3N4 photocatalyst for enhanced H2 evolution under simulated solar light irradiation. Chem. Eng. J. 2021, 421, 129687. [CrossRef]

15. Panikar, S.S.; Ramírez-García, G.; Banu, N.; Vallejo-Cardona, A.A.; Lugo, L.-F.; Camacho-Villegas, T.A.; Salas, P.; De la Rosa, E. Ligand-targeted Theranostic Liposomes combining Methylene Blue attached Upconversion nanoparticles for NIR activated Bioimaging and Photodynamic therapy against HER-2 positive breast cancer. J. Lumin. 2021, 237, 118143. [CrossRef]

16. Bai, X.; Wang, Y.; Song, Z.; Feng, Y.; Chen, Y.; Zhang, D.; Lin, F. The Basic Properties of AuNP and their Applications in Tumor Diagnosis and Treatment. Int. J. Mol. Sci. 2020, 21, 2480. [CrossRef]

17. Tai, Y.; Zhang, Y.; Sun, J.; Liu, F.; Tian, H.; Liu, Q.; Li, C. Y2O3:Yb3+, Tm3+/ZnO composite with a heterojunction structure and upconversion function for the photocatalytic degradation of organic dyes. RSC Adv. 2021, 11, 24044-24053. [CrossRef]

18. Tian, Y.; Liu, Q.; E, F.; Ye, R.; Chen, S.; Zhang, J.; Xu, S. Structural evolution, crystallization behaviour and mid-infrared emission properties in $\mathrm{Yb} /$ Ho codoped oxyfluoride germanosilicate glass ceramics with varied Si/Ge ratio. Infrared Phys. Technol. 2021, 116, 103741. [CrossRef]

19. Alvarez-Puebla, R.A.; Pazos-Perez, N.; Guerrini, L. SERS-fluorescent encoded particles as dual-mode optical probes. Appl. Mater. Today 2018, 13, 1-14. [CrossRef]

20. Xiong, J.; Li, G.; Zhang, J.; Li, D.; Pun, E.Y.B.; Lin, H. Fluorescence regulation derived from Eu3+ in miscible-order fluoridephosphate blocky phosphor. Nanotechnology 2021, 32, 435705. [CrossRef]

21. Zhang, Y.; Zhu, X.; Zhang, J.; Wu, Y.; Liu, J.; Zhang, Y. Synergistic upconversion photodynamic and photothermal therapy under cold near-infrared excitation. J. Colloid Interface Sci. 2021, 600, 513-529. [CrossRef] [PubMed]

22. Zhang, W.; Lu, Y.Y.; Zang, Y.; Xiong, Q.Y.; Xiong, J.P. Up-Conversion Nanomaterial Doped With Au Nanoparticles With Photothermal Conversion for Multi-Modality Imaging. 2021; in press . [CrossRef]

23. Zhang, Q.; Iwakuma, N.; Sharma, P. AuNPs as a contrast agent for in vivo tumor imaging with photoacoustic tomography. Nanotechnology 2009, 20, 395102. [CrossRef] [PubMed] 